\title{
Changes in Japanese Nurses' Awareness of Patient Interactions Following a Japanese Tea Ceremony
}

\author{
Mayumi Uno \\ Graduate School of Medicine Course of Health Science, Osaka University, Osaka, Japan \\ Email: unomayu@gmail.com
}

How to cite this paper: Uno, M. (2017) Changes in Japanese Nurses' Awareness of Patient Interactions Following a Japanese Tea Ceremony. Open Journal of Nursing, 7, 770-778.

https://doi.org/10.4236/ojn.2017.77058

Received: June 21, 2017

Accepted: July 17, 2017

Published: July 20, 2017

Copyright $\odot 2017$ by author and Scientific Research Publishing Inc. This work is licensed under the Creative Commons Attribution International License (CC BY 4.0).

http://creativecommons.org/licenses/by/4.0/

\section{(c) (i) Open Access}

\begin{abstract}
This study provided foundational data for use in nursing interventional methods for improving nurse-patient relationships. This was a descriptive study on the effectiveness of a Japanese tea ceremony (in Japanese: chado) intervention for improving nurse-patient relationships. I conducted a Japanese tea ceremony and examined changes in nurses' awareness regarding interactions with patients after this intervention. The tea ceremonies were conducted with the cooperation of an Urasenke tea ceremony lecturer. A quiet environment with chairs and tables was provided for all participants while they provided written answers to a descriptive survey, which was administered before and after the intervention; they required approximately $20 \mathrm{~min}$ to complete the survey. The mean length of each nurse's description was 800 characters. The tea ceremony was effective in bringing about definite changes in nurses' awareness concerning interactions with patients. This study is useful in that it suggests how nurses can maintain good interpersonal relationships with patients.
\end{abstract}

\section{Keywords}

Interventional Methods, Japanese Tea Ceremony, Nurse-Patient Relationships

\section{Introduction}

In recent years, the clinical practice, education, and research capabilities of nurses have increased; however, there remain complaints from patients and their family members concerning their interactions with nurses. To promote a sense of patient satisfaction during medical treatment, nurses should be aware of subservices that provide insight into the feelings of patients and that facilitate appropriate nurse-patient interactions [1]. Although the goals of nursing include 
consideration, compassion, and empathy toward patients, there is no concrete method of engendering these in a nurse.

Henderson (1964) noted that in the nurse-patient relationship, "getting under his/her skin" is a way to understand a patient [2]. Erikson (1997a) considered empathy to be "feeling concern for suffering," and showed that a nurse must acknowledge a patient's suffering to make the patient feel they are respected as a person [3]. To alleviate a patient's suffering, a nurse should discover the patient's desires, and the patient's feelings of trust, hope, powerlessness, guilt, and shame [4]. A nurse needs to understand each patient's unique experience of his or her disease, knowledge, and feelings [3] [5]. Such a nurse-patient relationship is considered the foundation of a therapeutic relationship.

Keenan (1996) reported that the Japanese tea ceremony is useful for stress management in nurses [6], and Donnelly (2007) reported that by placing participants within a natural setting [7], the tea ceremony allows participants to enjoy the life that is universally shared by humans and to maintain harmony with others. Uno (2015) reported on the importance of hospitality (in Japanese: omotenashi) in the Japanese culture as a characteristic of the nursing interactions that were desired by patients [8]. Although the Japanese tea ceremony is a part of the traditional Japanese culture, few Japanese individuals practice the art daily, and reports concerning the role of the tea ceremony in the field of nursing are rare. Thus, in this study, nurses who worked in a clinical practice participated in the Japanese tea ceremony to evaluate changes in their awareness with respect to their interactions with patients. I focused on the Japanese tea ceremony as a method to form peaceful interpersonal relationships during patient interactions.

This study provided basic data to explore interventional methods for nurses to improve nurse-patient relationships. I examined the manner in which awareness of the nurses regarding their patient interactions changed after participating in the Japanese tea ceremony.

\section{Methods}

This study was a descriptive survey of a Japanese tea ceremony intervention. In 2014, I conducted a similar intervention involving three participants and descriptive surveys, similar to those used in the present study. I confirmed that there were no mental or physical burdens on the participants and that there was a change in nurses' awareness.

\subsection{Participants}

I initially mailed 100 regional medical care support hospitals in the Kinki region of Japan to explain the purpose and methods of the study and to request their cooperation. Four hospitals agreed to cooperate. A total of 14 nurses expressed an interest in participating in the present study; however, only 12 nurses were included for analysis because two dropped out during the study. Twelve was the maximum number of individuals who agreed to cooperate. However, the 800 words provided in total by these individuals was sufficient for qualitative sum- 
marization.

\subsection{Data Collection}

The study period was from March to May 2015. Interventions were performed once per week over a 4-week period (i.e., a total of four times). Interventions were performed in a tea ceremony room located in a temple in the Osaka Prefecture, Japan.

\subsection{Ethical Considerations}

The participants received an explanation that data obtained from the study would not be used to identify any individual or for purposes other than research, would be strictly managed, and would be destroyed following the conclusion of the study. Cooperation was voluntary, and participants were assured that they would not be at a disadvantage if they decided not to participate. Furthermore, they were told that the program had no connection with evaluations at their affiliated hospital. The study was approved by the ethics review committee of participating hospitals in Osaka.

\subsection{Operational Definitions of the Terminology}

The "Japanese tea ceremony" (in Japanese: chado) is a traditional Japanese art that has been referred to as a "composite art form". "Tactfulness in silence" refers to the insight of sensing the thoughts and feelings of others that are not expressed in words.

\subsection{Study Design}

I administered a pre-intervention survey to assess the individual characteristics of the nurses (age, years of experience as a nurse, affiliated hospital wards, and experience participating in tea ceremonies) and the following items:

A. Interactions with nurses believed to be desired by patients,

B. Awareness of daily interactions with patients,

C. Interactions believed to improve the quality of nursing, and

D. Image of the tea ceremony.

A quiet environment with chairs and tables was provided for the participants while they provided written answers to the survey.

The tea ceremonies were conducted with the cooperation of an Urasenketea ceremony lecturer. The tea ceremony lecturer acted as the tea master during the ceremonies.

The guests were the participants, who were divided into groups of six individuals; each experienced the same program content for approximately $1 \mathrm{~h}$ in each session. To ease the tension of the participants who were participating in the tea ceremony for the first time, the researchers, who had participated in a tea ceremony before, presented a partial example of a ceremony. However, to avoid influencing the study results, the participants were allowed to act naturally during the tea ceremony (Figure 1 and Figure 2). The tea ceremony steps are listed 


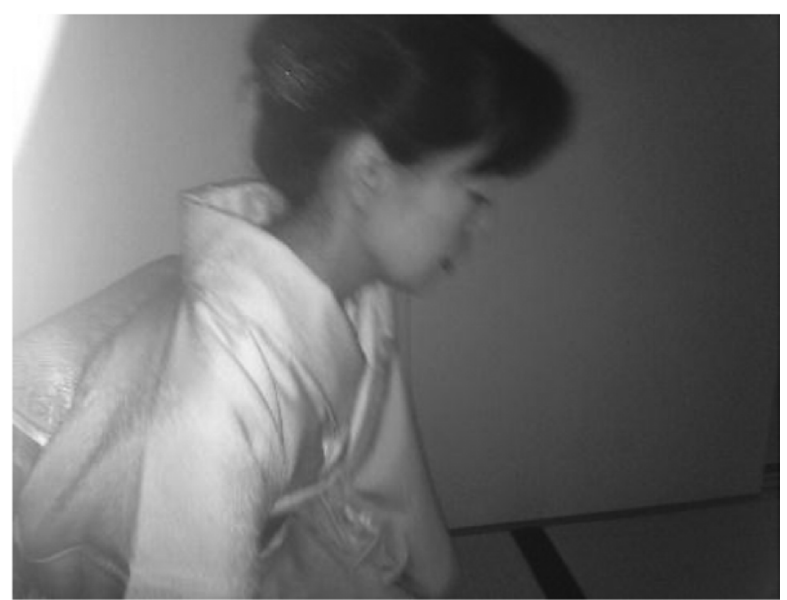

Figure 1. The manner of entering the tea ceremony room.

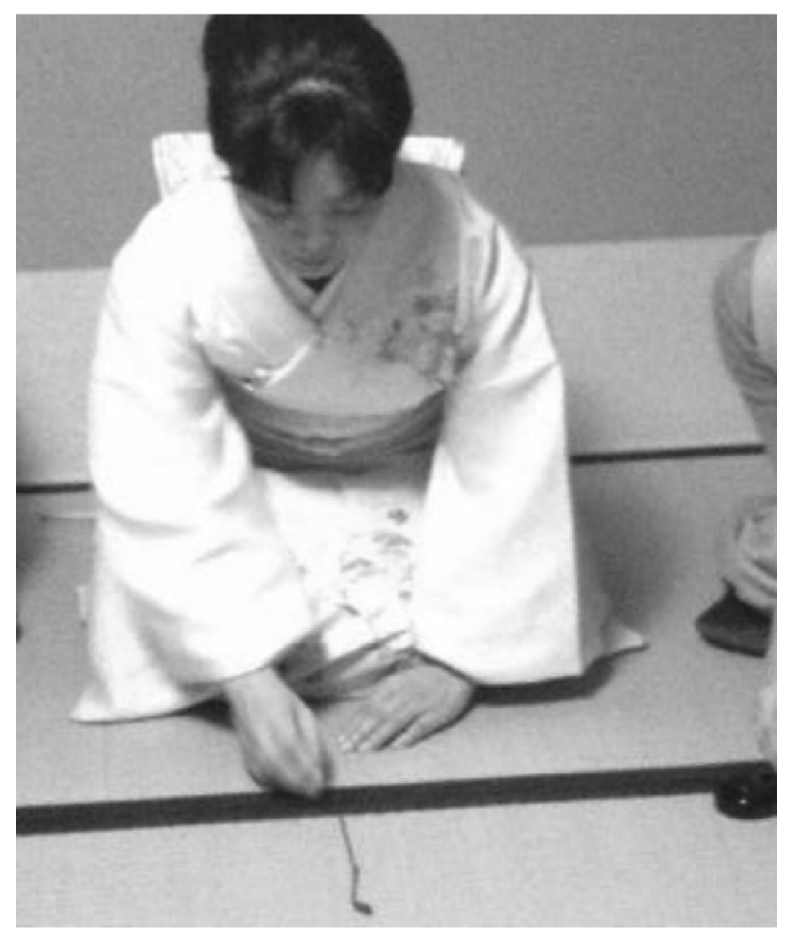

Figure 2. Method used by visitors.

below.

First, participants walked on paving stones in the tea ceremony garden and washed their hands in a stone washbasin in that garden (Figure 3). Then, they moved through a small door (in Japanese: nijiriguchi), by bending at the knee, to enter the tea ceremony room.

Second, the participants walked to the teahouse, sat quietly in the tea ceremony room, and read both the Zen Buddhist phrase on the hanging scroll in the room and on the teacups (Figure 4) while the tea master explained the tea ceremony process to them.

Third, they observed the water brazier and jar, which were to be used in the tea ceremony (Figure 5). 


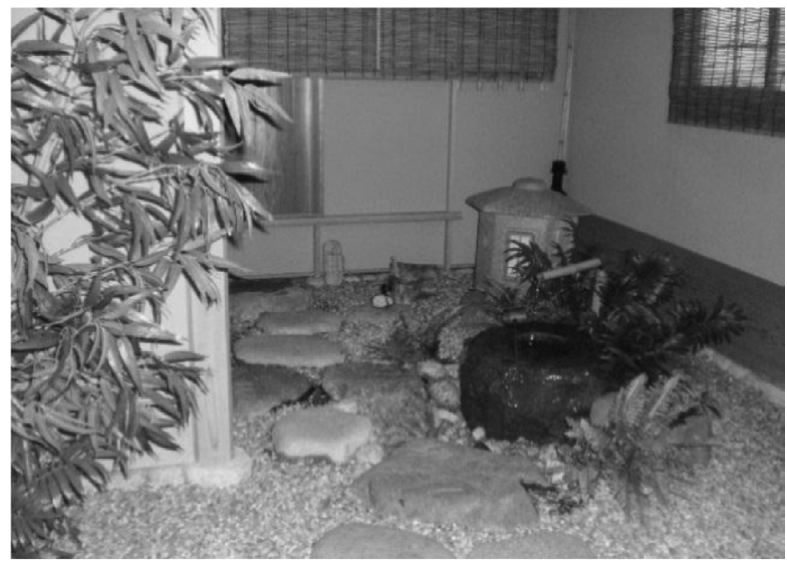

Figure 3. Approach to the tea ceremony room.

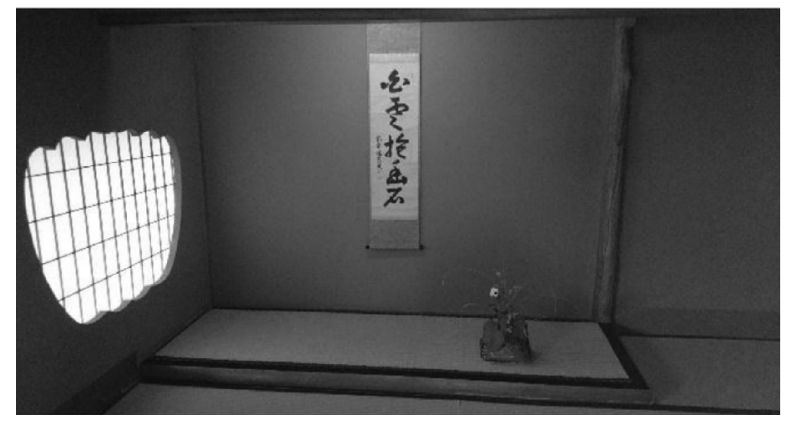

Figure 4. The hanging scroll featuring a Zen phrase, with flowers in the tea ceremony room.

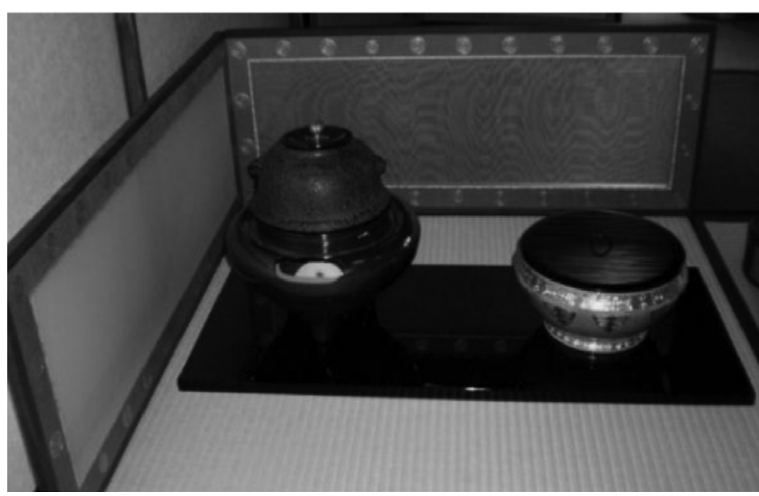

Figure 5. Water brazier and jar for the ceremony.

Fourth, they then smelled the incense (in Japanese: kiku), ate the Japanese confectioneries, and drank a cup of green tea (in Japanese: maccha).

Finally, the participants handled the tea ceremony utensils, incense, and teacups and received an explanation regarding the utensils to be used.

Each time, different Zen Buddhist phrases, flowers, Japanese confectioneries, and teacups were used to provide variety to the ceremonies. I administered a descriptive survey to the participants after the intervention, using methods similar to those used for the pre-intervention survey.

Data analysis compared the responses to $\mathrm{A}, \mathrm{B}, \mathrm{C}$, and $\mathrm{D}$, before and after the 
tea ceremony intervention.

\section{Results}

\subsection{Individual Characteristics}

The mean age of the 12 participants, all of whom were female, was 48 years (SD = 6.6). The mean years of nursing experience was $23(\mathrm{SD}=5.8)$. The nurses worked in the Department of Internal Medicine (chronic disease ward), and no participants had previous experience of participating in a tea ceremony (Table 1). Four of the nurses qualified at a university and eight were qualified as nurses at a vocational school.

\subsection{Nurse's Consciousness of Interactions with Patients before and after Intervention}

The participants required approximately $20 \mathrm{~min}$ to write their descriptions. The mean length of each nurse's description was 800 characters. The descriptions of items A through D were qualitatively analyzed and compared before and after the intervention (Table 2).

\section{Discussion}

Results of the pre-intervention awareness analysis revealed an awareness of appropriate professional interactions, such as "interacting gently and kindly", "interacting safely", "explanations and skills with a scientific basis", and "empathetic attitude". The Japanese tea ceremony involves silent communication between the host and guests, as the guests "sensitively feel the intentions of the tea master, who takes great pains to provide an atmosphere of hospitality". The post-intervention comments were related to peaceful interactions, such as "interacting without pressure", "interacting while maintaining an appropriate distance", "interacting with a sincere attitude", and "insight in sensing feelings that are not expressed in words". These categories were based on an awareness of the interactions with patients that were not limited to their status as a professional nurse.

Considering three aspects, I assessed how participant's awareness changed regarding interactions with patients after the tea ceremony. The first aspect was related to changes in feelings because of being in a teahouse and the formal interpersonal relationships that were created. After the intervention, categories related to calmness of mind were suggested by the nurses. For the nurses who were busy with daily nursing tasks, the Japanese tea ceremony was a place where they

Table 1. Demographic characteristics of nurses $(n=12)$.

\begin{tabular}{cc}
\hline Age (years) & \\
\hline Mean \pm SD & $48 \pm 6.6$ \\
\hline Working experience as a nurse (years) & $23 \pm 5.8$ \\
\hline Mean \pm SD & 23.8 \\
\hline
\end{tabular}


Table 2. Change in nurses' awareness following tea ceremony.

\begin{tabular}{|c|c|c|c|c|}
\hline & A & B & $\mathrm{C}$ & $\mathrm{D}$ \\
\hline & $\begin{array}{l}\text { Interactions with } \\
\text { nurses believed to } \\
\text { be desired by } \\
\text { patients }\end{array}$ & $\begin{array}{l}\text { Awareness of daily } \\
\text { interactions with } \\
\text { patients }\end{array}$ & $\begin{array}{l}\text { Interactions } \\
\text { believed to } \\
\text { improve the } \\
\text { quality of nursing }\end{array}$ & $\begin{array}{l}\text { Image of tea } \\
\text { ceremony }\end{array}$ \\
\hline \multirow[t]{5}{*}{ Before } & Smile & $\begin{array}{l}\text { Interact gently and } \\
\text { kindly }\end{array}$ & Keep learning & Stiff \\
\hline & Kindness & Interact safely & $\begin{array}{c}\text { Learn and } \\
\text { practice ways of } \\
\text { communicating } \\
\text { regarding disease }\end{array}$ & Difficult \\
\hline & Communication & $\begin{array}{l}\text { Explanations and } \\
\text { skills provided with a } \\
\text { scientific basis }\end{array}$ & $\begin{array}{l}\text { Always think } \\
\text { about the } \\
\text { patient's feelings }\end{array}$ & Unfamiliar \\
\hline & Explanation & Empathetic attitude & $\begin{array}{c}\text { Do not make } \\
\text { medical mistakes, } \\
\text { etc. }\end{array}$ & $\begin{array}{l}\text { Only some } \\
\text { rich people } \\
\text { learn }\end{array}$ \\
\hline & & & $\begin{array}{l}\text { Provide a good } \\
\text { recuperative } \\
\text { environment }\end{array}$ & \\
\hline \multirow[t]{4}{*}{ After } & $\begin{array}{l}\text { Not superficial } \\
\text { gentleness; treat } \\
\text { patient as a person } \\
\text { Understand what } \\
\text { the patient wants, } \\
\text { by understanding } \\
\text { his/her nonverbal } \\
\text { communication }\end{array}$ & $\begin{array}{l}\text { Interact without } \\
\text { pressure }\end{array}$ & $\begin{array}{c}\text { Always remind } \\
\text { yourself how } \\
\text { casual and caring } \\
\text { you are } \\
\text { Catch precisely as } \\
\text { soon as possible } \\
\text { Touch according } \\
\text { to the patient's } \\
\text { desire }\end{array}$ & $\begin{array}{c}\text { Can be } \\
\text { incorporated } \\
\text { into daily life }\end{array}$ \\
\hline & $\begin{array}{l}\text { I deeply feel what } \\
\text { you want }\end{array}$ & $\begin{array}{c}\text { Interact while } \\
\text { maintaining an } \\
\text { appropriate distance }\end{array}$ & $\begin{array}{l}\text { As a professional, } \\
\text { it is better to } \\
\text { avoid using } \\
\text { technical terms as } \\
\text { much as possible }\end{array}$ & $\begin{array}{l}\text { The spirit of } \\
\text { the tea } \\
\text { ceremony } \\
\text { adapts to the } \\
\text { Japanese } \\
\text { people }\end{array}$ \\
\hline & $\begin{array}{l}\text { Treat the individual } \\
\text { as a someone who } \\
\text { is a part of nature }\end{array}$ & $\begin{array}{l}\text { Interact with a } \\
\text { sincere attitude }\end{array}$ & $\begin{array}{l}\text { Try to use the } \\
\text { senses, such as in } \\
\text { the manner of } \\
\text { touching } \\
\text { Empathic } \\
\text { understanding }\end{array}$ & $\begin{array}{l}\text { Become the } \\
\text { starting point } \\
\text { of how to } \\
\text { contact } \\
\text { people }\end{array}$ \\
\hline & $\begin{array}{l}\text { As a nurse, explain } \\
\text { what is expected of } \\
\text { the patient }\end{array}$ & $\begin{array}{l}\text { Insight in sensing } \\
\text { feelings that are not } \\
\text { expressed by words }\end{array}$ & $\begin{array}{l}\text { Even just going to } \\
\text { a room and } \\
\text { talking is part of } \\
\text { the nurse's job }\end{array}$ & $\begin{array}{l}\text { My own } \\
\text { heart calms } \\
\text { down }\end{array}$ \\
\hline
\end{tabular}

could relax and find peace of mind. The second aspect was that the participants (nurses) received polite hospitality and were cared for. People tend to be rude to others when they are treated rudely themselves. The work of nurses constitutes emotional labor, that is, the management of emotions in the workplace [9]. After 
the intervention, the categories "interacting with a sincere attitude" and "insight in sensing feelings that are not expressed in words" were observed. Therefore, the tea ceremony is useful for controlling emotions through polite hospitality and caring for guests.

The third aspect was the way in which the five senses were utilized. Nurses should have a high degree of sensitivity while working in a hectic and highly stressful environment. However, here the participants were given a chance to return to nature by appreciating seasonal flowers. That is, the participants were able to relax in a beautiful environment that could be experienced through the five senses. These findings are important for managing the working environment of nurses, who are likely busy with numerous other daily tasks when interacting with patients.

The program used in this study exceeded the limits of the field of nursing, but it appeared useful for creating favorable nurse-patient relationships. Specifically, this method effectively relaxed the nurses, which suggests that relaxation is one way to improve interpersonal relationships. In summary, the intervention method used in this study is useful for nurses to maintain good interpersonal relationships with patients.

\section{Conclusion}

Changes in nurses' awareness related to interactions with patients were noted after the tea ceremony intervention. I observed changes related to increased functional beauty and spirituality, as exemplified by the categories "interacting without pressure", "interacting while maintaining an appropriate distance", "interacting with a sincere attitude", and "insight in sensing feelings that are not expressed in words". Thus, participating in the tea ceremony was effective in bringing about definite changes in nurses' awareness concerning interactions with patients. However, a future study with an increased sample size is needed to verify the present study's results, and a survey of patients who received nursing care from the participants is also necessary.

\section{Acknowledgements}

I am deeply indebted to the nurses who understood the purpose and kindly cooperated in this study and to the Urasenke tea ceremony lecturer.

\section{Funding}

The study received no external funding.

\section{Conflict of Interest}

The author declares that no conflict of interest exists.

\section{References}

[1] Uno, M., Tsujimoto, T. and Inoue, T. (2014) Effect of Conflicts in Patient-Nurse Relations. Nursing Journal Osaka University, 20, 47-53. [in Japanese] 
[2] Henderson, V. (1964) The Nature of Nursing. American Journal of Nursing, 64, 62-68. https://doi.org/10.1097/00000446-196408000-00029

[3] Eriksson, K. (1997a) Understanding the World of the Patient, the Suffering Human Beings: The New Clinical Paradigm from Nursing to Caring. Advanced Practice Nursing Quarterly, 3, 8-13.

[4] Erikson, K. (1997b) Caring, Spirituality and Suffering. In: Roach, M.S., Ed., Caring from the Heart. The Convergence of Caring and Spirituality, Paulist Press, Mahwah, NJ, 81.

[5] Beech, P. and Norman, I.J. (1995) Patients' Perception of the Quality of Psychiatric Nursing Care: Findings from a Small-Scale Descriptive Study. Journal of Clinical Nursing, 4, 117-123. https://doi.org/10.1111/j.1365-2702.1995.tb00019.x

[6] Keenan, J. (1996) The Japanese Tea Ceremony and Stress Management. Holistic Nursing Practice, 10, 30-37. https://doi.org/10.1097/00004650-199601000-00005

[7] Donnelly, G. F. (2007) The Tea Ceremony: Connecting with Self and Others. Holistic Nursing Practice, 21, 215. https://doi.org/10.1097/01.hnp.0000287983.71602.f3

[8] Uno, M. (2015) A Study Using SERVQUAL to Evaluate Trends in Patient Expectations When Conflict Arises. Journal of Yamato University, 1, 173-179.

[9] Hochschild, A. (1983) The Management Heart: Commercialization of Human Feelings. University of California Press, Berkeley.

Submit or recommend next manuscript to SCIRP and we will provide best service for you:

Accepting pre-submission inquiries through Email, Facebook, LinkedIn, Twitter, etc. A wide selection of journals (inclusive of 9 subjects, more than 200 journals)

Providing 24-hour high-quality service

User-friendly online submission system

Fair and swift peer-review system

Efficient typesetting and proofreading procedure

Display of the result of downloads and visits, as well as the number of cited articles

Maximum dissemination of your research work

Submit your manuscript at: http://papersubmission.scirp.org/

Or contact ojn@scirp.org 